\title{
Text Messages to Promote Secondary Prevention after Acute Coronary Syndrome (IMPACS trial)
}

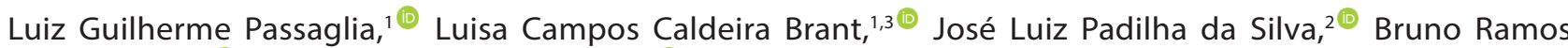 \\ Nascimento, ${ }^{1,3 \oplus}$ Antônio Luiz Pinho Ribeiro ${ }^{1,3}(1$ \\ Hospital das Clínicas da Universidade Federal de Minas Gerais, ${ }^{1}$ Belo Horizonte, MG - Brazil \\ Universidade Federal do Paraná, ${ }^{2}$ Curitiba, PR - Brazil \\ Departamento de Clínica Médica, Faculdade de Medicina, Universidade Federal de Minas Gerais, ${ }^{3}$ Belo Horizonte, Brazil
}

\section{Abstract}

Background: Short message service (SMS) to promote healthcare improves the control of cardiovascular risk factors, but there is a lack of evidence in low and middle-income countries, particularly after acute coronary syndromes (ACS).

Objective: This study aims to evaluate whether the use of SMS increases risk factor control after hospital discharge for ACS.

Methods: IMPACS is a 2-arm randomized trial with 180 patients hospitalized due to ACS at a tertiary hospital in Brazil. Eligible patients were randomized (1:1) to an SMS intervention (G1) or standard care (G2) upon hospital discharge. The primary endpoint was set to achieve 4 or 5 points in a risk factor control score, consisting of a cluster of 5 modifiable risk factors: LDL-C $<70 \mathrm{mg} / \mathrm{dL}$, blood pressure (BP) $<140 / 90 \mathrm{mmHg}$, regular exercise ( $\geq 5$ days/week, 30 minutes/session), nonsmoker status, and body mass index (BMI) $<25 \mathrm{~kg} / \mathrm{m} 2$ ] at 6 months. Secondary outcomes were components of the primary outcome plus rehospitalization, cardiovascular death, and death from any cause. Results are designated as significant if $\mathrm{p}<0.05$.

Results: From randomized patients, 147 were included in the final analysis. Mean age was 58 (51-64) years, 74\% males. The primary outcome was achieved by $12(16.2 \%)$ patients in G1 and $15(20.8 \%)$ in G2 (OR=0.73, $95 \% \mathrm{CI}$ 0.32-1.70, $\mathrm{p}=0.47)$. Secondary outcomes were also similar: LDL-C $<70 \mathrm{mg} / \mathrm{dl}(\mathrm{p}=0.33), \mathrm{BP}<140 / 90 \mathrm{mmHg}(\mathrm{p}=0.32)$, non-smoker $(p=0.74)$, regular exercise $(p=0.97), B M I(p=0.71)$, and rehospitalization $(p=0.06)$. Death from any cause occurred in three participants $(2 \%)$, including one cardiovascular death in each group.

Conclusion: SMS intervention did not significantly improve cardiovascular risk factor control when compared to standard care in patients discharged after ACS in Brazil.

Keywords: Acute Coronary Syndrome; Text Messages; Risk Factors; Telemedicine.

\section{Introduction}

Ischemic heart disease is the leading cause of death and loss of cardiovascular health worldwide. ${ }^{1}$ In Brazil, although age-standardized cardiovascular mortality rate has declined in recent decades, coronary heart disease also remains the leading cause of death. ${ }^{2-3}$ The increasing prevalence of cardiovascular risk factors, due to growing urbanization, is involved in this scenario. ${ }^{4}$
The twentieth century has witnessed a remarkable evolution in the understanding of pathogenesis, treatment, and clinical consequences of coronary atherosclerosis. ${ }^{5}$ Despite the progress that has been achieved, the risk of reinfarction or death after the first coronary event remains high. ${ }^{6}$ Given the importance of secondary prevention after an acute coronary syndrome (ACS), ${ }^{7-9}$ several electronic health tools are available for use. Therefore, short message service (SMS) is a simple and low-cost alternative tool that enables encouragement of healthy living habits. ${ }^{10}$

Mailing Address: Luiz Passaglia

Avenida Alfredo Balena, 110. Postal Code: 30130-100, Santa Efigênia, Belo Horizonte, MG - Brazil.

E-mail: Ig.passaglia@uol.com.br 
A previous randomized study developed in a high-income country, the "TEXT ME" trial, ${ }^{11}$ showed positive results of using SMS in patients with coronary heart disease. Despite the promising results, there is insufficient evidence to draw definite conclusions about SMS interventions in low and middle-income countries (LMIC), not only because most studies were performed in high-income countries, ${ }^{10-12}$ but also because significant barriers can hamper the successful application of mobile Health (mHealth) in this setting. ${ }^{13}$ Furthermore, good adherence to drug therapy is associated with positive health outcomes, ${ }^{14}$ and treatment adherence after SCA continues to be an important condition to achieve optimal targets. ${ }^{8}$ The IMPACS (Impact of text Messages to $\underline{\text { Promote }}$ secondary prevention after $\underline{\text { Acute }}$ Corornary $\underline{\text { Syndrome) study }}$ aims to further assess this gap through a randomized clinical trial, evaluating whether the use of SMS increases risk factor control after hospital discharge for ACS at a tertiary hospital in Brazil.

\section{Methods}

\section{Design and Participants}

The IMPACS trial is a two-arm, parallel, doubleblind randomized trial involving patients admitted due to ACS at the University Hospital of Universidade Federal de Minas Gerais (UFMG), a tertiary, public, and general hospital in Belo Horizonte, a capital city located in southeast Brazil. Details of the trial design have been previously published, ${ }^{15}$ and the protocol was approved by institutional review boards.

Patients of 18 years of age or older, who were hospitalized with a diagnosis of ACS, were discharged for outpatient follow-up, and were able to receive SMS in their own mobile phone, were eligible to participate in this study. Eligible patients were identified by daily assessment in the Coronary Intensive Care Unit and followed up during hospitalization for data collection. Data were collected in standard protocols by previously trained cardiologists and medical students. Exclusion criteria included the refusal or inability to sign the Informed Consent, as well as complete illiteracy (the inability to read and write). Included patients were also participants of the "Good Practice Program in Cardiology / Get With The Guidelines", ${ }^{16}$ a joint quality improvement program of the Brazilian Cardiology Society, Ministry of Health (Brazil) and American Heart Association (US).

\section{Randomization}

After obtaining informed written consent, data from each patient was entered into an online database (RedCap). A blocked randomization was provided in blocks of four patients each, following the date of patient enrollment, following a uniform 1:1 fashion. Researchers, data collectors, and physicians who provided medical care were blinded to the treatment allocation. Dedicated software developed by the Telehealth Center of UFMG's University Hospital sent one-way SMS between a server (Microsoft Windows ${ }^{\circledast}$, Redmond, WA, US) and the participant's mobile phone, ${ }^{17}$ The software had a bank of 185 text messages that allowed for the identification and scheduling of the submission of SMS on predetermined dates. Interactive communication was not available.

\section{Interventions}

The usual care group (IMPACS control group) received standard discharge care after ACS. The intervention group (IMPACS intervention group) also received standard discharge care, plus the SMS intervention program. The usual discharge care in the first 6 months of follow-up after ACS consisted of at least two medical appointments with the attending cardiologist, one appointment with a clinical pharmacist, and one appointment with the physical therapy group. All discharged patients were given the opportunity to participate in the hospital cardiovascular rehabilitation program, which consists of supervised physical exercise for three consecutive months. More appointments could occur, according to the evaluation of the attending health professionals. IMPACS researchers were independent of attending physicians and did not interfere with patient care.

A total of 185 SMS was developed by the research group, offering advice, motivation, and information about medication adherence, increase in regular physical activity, adoption of healthy dietary habits, and smoking cessation (if appropriate). The Intervention group was divided into four subgroups ("modules"), according to baseline characteristics of participants: Module 1 , nonsmokers and free of diabetes; Module 2, nonsmokers and diabetic patients; Module 3, smokers and non-diabetic patients; Module 4, smokers and diabetic patients. Semi-personalized SMS were sent out foud times per week for six months, with the first SMS being sent immediately after hospital discharge. The system could not inform whether the patients read the messages. No cross-over between modules was permitted, even 
if the patient stopped smoking or developed diabetes. Examples of text messages can be seen in the previously published trial protocol. ${ }^{15}$

\section{Outcomes}

Outcomes were evaluated $6( \pm 1)$ months after hospital discharge, in a pre-scheduled follow-up appointment. The primary endpoint was set to achieve 4 or 5 points in a Risk Factor Control Score, which combined the cluster effect of five main modifiable risk factors for ACS (Low Density Lipoprotein Cholesterol (LDL-C) $<70 \mathrm{mg} / \mathrm{dL}$, blood pressure $<140 / 90 \mathrm{mmHg}$, regular exercise $[\geq 5$ days/ week $\times 30$ minutes of moderate exercise per session], nonsmoker status, and body mass index (BMI) $\left.<25 \mathrm{~kg} / \mathrm{m}^{2}\right)$.

Pre-specified secondary endpoints were: plasma LDL-C levels, level of physical activity (measured by a "direct" question [participants who reported exercising 5 or more days per week $\times 30 \mathrm{~min} / \mathrm{d}$ of moderate exercise], and by Portuguese version of the International Physical Activity Questionnaire Short Form (IPAQ$\mathrm{SF})^{18}$ - Supplementary Material, which was planned to be validated by using accelerometers in one-fifth of the participants), blood pressure levels, medication adherence "(measured via the "Medida de Adesão aos Tratamentos" - Treatment Adherence Measure [MAT] form ${ }^{19}$ ), proportion of non-smokers (self-reported and confirmed by a Carbon Monoxide Meter Breath Test), BMI, rehospitalization, cardiovascular death, and death from any cause. Additional analyses were done using a Health Literacy questionnaire (The Short Assessment of Health Literacy for Portuguese Speaking Adults - SAHLPA- $18,{ }^{20}$ with a score ranging from 0 to 18 , with $\leq 14$ indicating inadequate health literacy), and a follow-up questionnaire (self-reported acceptability and understanding). Both instruments were applied for a better interpretation of trial results due to LMIC's barriers and particularities.

\section{Statistical methods}

A sample size of 160 patients was calculated to provide $80 \%$ power to detect a difference of at least $19 \%$ between the intervention and the control groups in achieving 4 or more of the 5 modifiable risk factors (Risk Factor Control Score), with a two-sided significance level of 0.05 , considering a loss to follow-up of 20 patients. This calculation was based on findings from the TEXT ME trial. ${ }^{11}$ Pre-specified interim analysis, performed before the end of patient allocation, found follow-up losses higher than expected, and the sample size was recalculated to 180 patients to maintain an $80 \%$ power in the outcome analyses.

Analyses were performed according to the intentionto-treat principle. For the baseline characteristics, continuous variables were summarized as mean \pm standard deviation (SD) or as median and first and third quartiles (Q1, Q3), as appropriate, and groups compared using unpaired Student's t-test or Mann-Whitney test, based on the distribution pattern (Shapiro-Wilk test was used for this purpose). Categorical variables were expressed as proportions and groups compared by chisquare test. The primary and secondary outcomes were compared between groups by means of the chi-square test, and the results were presented as odds ratios with 95\% confidence intervals (CI). For the additional analyses, the questionnaires were expressed as categorical variables, and the groups were compared by the chisquare test for the primary outcome, when appropriate. A per-protocol analysis was done using the results of the follow-up questionnaire.

A longitudinal post-hoc analysis was carried out considering the baseline values. Marginal models for longitudinal data were adjusted via generalized estimation equations - with independent correlation matrix and robust variance (sandwich estimator). The link function used here was the identity for continuous responses and logit for binary responses, which allows for interpretation in terms of mean differences and odds ratios, respectively. The models included the main effects of group and time in addition to the group $x$ time interaction, which, being statistically significant, would indicate a different evolution of the groups over time. Statistical significance was set at $\alpha=0.05$ for all analyses.

The statistical analysis was conducted using SPSS Statistics, version 20.1 for Windows (IBM Corp, Armonk, NY, US), and the R statistical software, version 3.6.3, expanded by the packages foreign, tidyverse, ggplot2, gridExtra, and geepack.

\section{Results}

From December 2017 to December 2018, 310 eligible patients were screened. A total of 180 patients were randomly assigned to receive either usual care or usual care plus SMS intervention. At \pm 6 months after hospital discharge, 13 participants in the intervention group $(14.4 \%)$ and 17 participants in the control group (18.9\%) did not attend the scheduled appointment, even though 
they were personally contacted through their cell phone. Including losses due to death $(n=3)$, a total of 15 patients in the intervention group (16.7\%) and 18 patients in the control group $(20.0 \%)$ did not complete the planned follow-up. The last 6-month follow-up visit was done in June 2019, and 147 patients were included in the primary analysis (Figure 1).

During the index hospitalization, baseline characteristics were similar between groups, including the characterization of ACS, coronary artery disease severity, clinical data, and medications upon discharge (Table 1).

The primary endpoint was achieved by 12 participants $(16.2 \%)$ in the intervention group and by 15 participants $(20.8 \%)$ in the control group $(\mathrm{p}=0.473)$ (Table 2$)$.

The incidence of secondary endpoints is also shown in Table 2. All pre-specified endpoints were similar between the intervention and control groups, including the LDL-C level $<70 \mathrm{mg} / \mathrm{dL}$ ( $\mathrm{p}=0.335$ ), blood pressure $<140 \times 90 \mathrm{mmHg}$ $(\mathrm{p}=0.324)$, performing regular exercise (more than 150 min/week) $(p=0.973)$, nonsmoker status $(p=0.741), B M I$ $<25 \mathrm{Kg} / \mathrm{m}^{2}(\mathrm{p}=0.710)$, and medication adherence $(\mathrm{p}=0.297)$. Rehospitalization occurred in 39 participants (26\%), with a trend to lower hospitalization rates in the intervention group ( $\mathrm{p}=0.062$ ). Death from any cause occurred in three participants $(2 \%)$ in the entire study, including one cardiovascular death for each group.

At the 6-month follow-up visit, the intervention and control groups had, respectively, similar results in the measures of median LDL-C, mean systolic blood pressure, mean diastolic blood pressure, and median BMI. Medications at 6 months, including aspirin, statin, and beta-blockers, as well as achievement of 3 to 5 points in the Risk Factor Control Score were similar between the groups (Table 3).

In view of a small sample size, a longitudinal post hoc analysis was carried out. Different lines were estimated for each group, connecting baseline and 6-month follow-up data, not assuming baseline equality despite randomization (Figure 2). Taking this model into account, time interaction (effect of time) was observed for the primary outcome and for four of the five secondary components of the primary outcome: LDL-C level $<70 \mathrm{mg} / \mathrm{dL}$, blood pressure $<140 \times 90 \mathrm{mmHg}$, performing regular exercise (more than $150 \mathrm{~min} /$ week), nonsmoker status. BMI<25 Kg/ $\mathrm{m}^{2}$ was the only outcome without time interaction.
Otherwise, no statistical significance was found when the treatment $x$ time interaction was considered (group effect), which indicates that the intervention and control groups followed lines that did not differ over time.

Regarding the health literacy evaluation, 79 (43.9\%) participants in both groups achieved more than 14 points in SAHLPA-18 (Table 1). For the primary outcome, achieving 4 or 5 in a Risk Factor Control Score occurred in 10 participants $(15.9 \%)$ in the group with adequate literacy and in 17 participants $(20.7 \%)$ in the group with inadequate health literacy $(\mathrm{OR}=0.72 ; 95 \%$ CI 0.30-1.70; $\mathrm{p}=0.456$ ).

The follow-up questionnaire (acceptability and understanding) applied at \pm 6 months showed that 20 participants in the intervention group (27\%) did not receive IMPACS SMS (Table S1 - Supplementary material), by self-report, although the SMS were sent by the software. Given these findings, a perprotocol analysis was performed: participants in the intervention group who confirmed that they had received SMS were compared to the control group plus participants in the intervention group who did not read SMS. The primary and secondary outcomes were similar between the two (Table 4), except for the rate of rehospitalization $(\mathrm{p}=0.026)$, which proved to be lower in the intervention group.

The results of the IPAQ-SF and accelerometer users are shown in Supplementary material (Table S2 and S3, respectively). Baseline characteristics of participants who used accelerometers for physical activity analyses were similar between the groups (Table S4 - Supplementary material). Moderate physical activity measured by accelerometer was higher in the intervention group (225 $\mathrm{min} /$ week) than in the control group (114 min/week) (Mean Difference 111 min/week; 95\% CI33-189; p=0.007), although IPAQ-SF Questionnaire results were similar between the two.

\section{Discussion}

In this randomized clinical trial involving patients hospitalized with ACS and discharged for outpatient follow-up at a public general university hospital in Brazil, the primary composite outcome - achieving 4 to 5 points in a Risk Factor Control Score - was similar between patients under usual care compared to those additionally receiving an SMS intervention program for secondary 


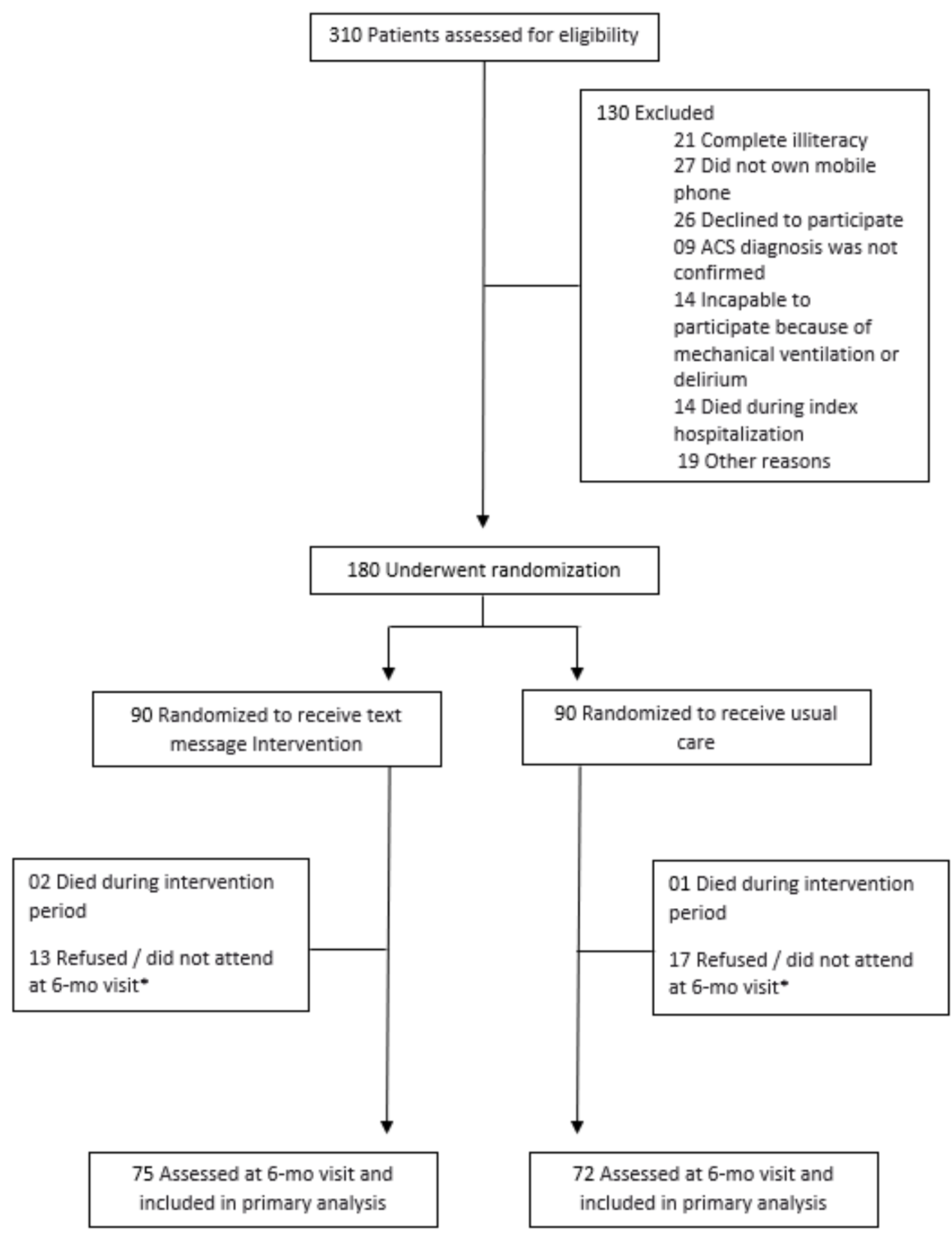

Figure 1 - Enrollment of Participants in the IMPACS Trial * All patients were contact by phone at 6 months after hospital discharge, and they were still alive. However, some of them refused to come to the 6-month follow-up appointment; others did not attend the scheduled appointment exceeding the expected follow-up period of the study (6 months \pm 1 month). 
Table 1 - Baseline Characteristics

\begin{tabular}{|c|c|c|c|c|c|c|}
\hline \multicolumn{3}{|l|}{ Characteristic } & Total (180) & Intervention (90) & Control (90) & p-value \\
\hline \multicolumn{3}{|c|}{ Median age (IQR) - yr } & $58.0(51.0-64.0)$ & $57.5(50.7-63.0)$ & $58.0(51.0-65.0)$ & 0.601 \\
\hline \multicolumn{3}{|l|}{ Male sex - no. $(\%)$} & $134 / 180(74.4)$ & $65(72.2)$ & $69(76.7)$ & 0.494 \\
\hline \multicolumn{3}{|c|}{ Education level ( $\leq 9$ years) - no. $(\%)$} & $107 / 130(59.4)$ & $51(56.7)$ & $56(62.2)$ & 0.448 \\
\hline \multicolumn{3}{|c|}{$\begin{array}{l}\text { Household Financial Indicator ( } \leq 5 \text { Brazil minimum } \\
\text { monthly salary })- \text { no. }(\%)\end{array}$} & $155 / 180(86.1)$ & $73(81.1)$ & $82(91.1)$ & 0.052 \\
\hline \multicolumn{3}{|c|}{ Hypertension } & $128 / 180(71.1)$ & $69(76.7)$ & $59(65.6)$ & 0.100 \\
\hline \multirow{11}{*}{$\begin{array}{l}\text { Disease history - } \\
\text { no. (\%) }\end{array}$} & \multicolumn{2}{|l|}{ Dyslipidemia } & 63/180 (35) & $31(34.4)$ & $32(35.6)$ & 0.876 \\
\hline & \multicolumn{2}{|l|}{ Diabetes } & $39 / 180(21.7)$ & $18(20.0)$ & $21(23.3)$ & 0.587 \\
\hline & \multicolumn{2}{|c|}{ Use of insulin for diabetes } & $16 / 180(8.9)$ & $5(5.6)$ & $11(12.2)$ & 0.116 \\
\hline & \multicolumn{2}{|c|}{ Peripheral artery disease } & $4 / 180(2.2)$ & $2(2.2 \%)$ & $2(2.2 \%)$ & 1.000 \\
\hline & \multicolumn{2}{|c|}{ Smoker (former and current) } & $124 / 180(68.9)$ & $64(71.1)$ & $60(66.7)$ & 0.520 \\
\hline & \multicolumn{2}{|c|}{ Current smoker } & $65 / 180(36.1)$ & $36(40.0)$ & $29(32.2)$ & 0.277 \\
\hline & \multicolumn{2}{|c|}{ Previous myocardial infarction } & $41 / 180(22.8)$ & $21(23.6)$ & $20(22.2)$ & 0.827 \\
\hline & \multicolumn{2}{|l|}{ Previous PCI } & 25/180 (13.9) & $13(14.4)$ & $12(13.3)$ & 0.829 \\
\hline & \multicolumn{2}{|c|}{ Family history of CAD } & $78 / 180(43.3)$ & $42(46.7)$ & $36(40.0)$ & 0.367 \\
\hline & \multicolumn{2}{|l|}{ Use of statin } & $59 / 180(32.8)$ & $24(26.7)$ & $35(38.9)$ & 0.081 \\
\hline & \multicolumn{2}{|c|}{ Use of aspirin } & $50 / 180(27.8)$ & $22(24.4)$ & $28(31.5)$ & 0.296 \\
\hline \multirow{8}{*}{ ACS - no. (\%) } & \multirow{3}{*}{ Description } & STEMI & $122 / 180(67.8)$ & $58(64.4)$ & $64(71.1)$ & \multirow{3}{*}{0.403} \\
\hline & & NSTEMI & 33/180 (18.3) & $20(22.2)$ & $13(14.4)$ & \\
\hline & & Unstable angina & 25/180 (13.9) & $12(13.3)$ & $13(14.4)$ & \\
\hline & \multirow{2}{*}{ STEMI } & Primary PCI & 48/122 (39.3) & $21(23.9)$ & $27(30.0)$ & \multirow{2}{*}{0.368} \\
\hline & & Thrombolytic therapy & $49 / 122(40.1)$ & $23(26.1)$ & $26(28.9)$ & \\
\hline & \multicolumn{2}{|c|}{ Killip class $\geq \mathrm{II}$} & $45 / 180(25)$ & $19(21.1)$ & $26(28.9)$ & 0.623 \\
\hline & \multicolumn{2}{|l|}{ PCI } & $105 / 180(58.3)$ & $48(53.3)$ & $57(63.3)$ & 0.174 \\
\hline & \multicolumn{2}{|c|}{ CABG surgery } & $9 / 180(5 \%)$ & $7(7.8)$ & $2(2.2)$ & 0.169 \\
\hline & No significan & coronary stenosis & 26/177 (14.7) & $14(15.9)$ & $12(13.5)$ & \\
\hline CAD severity & 1-Vessel dise & & 66/177 (37.3) & $29(33.0)$ & 37 (41.6) & \\
\hline - no. $(\%)$ & 2-Vessel dise & & $47 / 177(26.5)$ & $26(29.5)$ & 21 (23.6) & \\
\hline & 3-Vessel dise & & $38 / 177(21.5)$ & $19(21.3)$ & 19 (21.6) & \\
\hline & Left ventricu & r ejection fraction & $52.3( \pm 12.1)$ & $52.4( \pm 11.9)$ & $52.2( \pm 12.3)$ & 0.937 \\
\hline & Exercising re & ularly & 29/179 (16.2) & $11(12.4)$ & $18(20.0)$ & 0.165 \\
\hline & BMI -- $\mathrm{Kg} / \mathrm{m}^{2}$ & & $28.4( \pm 4.7)$ & $28.3( \pm 5.0)$ & $28.6( \pm 4.5)$ & 0.715 \\
\hline & Total Cholest & $\mathrm{rol}-\mathrm{mg} / \mathrm{dL}$ & $170.8( \pm 45)$ & $173.4( \pm 48.1)$ & $168.2( \pm 41.7)$ & 0.443 \\
\hline Clinical Data- & LDL-C - mg & & $99.7( \pm 41.7)$ & $103.8( \pm 44.3)$ & $95.8( \pm 38.9)$ & 0.203 \\
\hline Mean (SD), no. & HDL-C $-\mathrm{mg}$ & dL (IQR) & $42.0(35.0-49.0)$ & $42.0(35.0-49.0)$ & $41.5(34.7-49.2)$ & 0.466 \\
\hline (IQR) & Triglycerides & $-\mathrm{mg} / \mathrm{dL}$ & $129.0(90.7-181.7)$ & $124.5(96.2-188.7)$ & $139.5(87.7-177.2)$ & 0.748 \\
\hline & Systolic Bloo & pressure $-\mathrm{mmHg}$ & $113.0(102.0-124.0)$ & $114.5(104.2-124.7)$ & $110.0(100.0-119.2)$ & 0.067 \\
\hline & Diastolic Bloc & $\mathrm{d}$ pressure $-\mathrm{mmHg}$ & $70.5( \pm 10.9)$ & $71.5( \pm 11.6)$ & $69.4( \pm 10.2)$ & 0.200 \\
\hline & Heart rate- & $\min$ & $70.0(62.0-81.0)$ & $70.0(61.0-80.0)$ & $72.0(63.7-81.0)$ & 0.212 \\
\hline & Creatinine le & $\mathrm{el}-\mathrm{md} / \mathrm{dL}$ & $1.02(0.86-1.19)$ & $1.04(0.86-1.19)$ & $0.98(0.85-1.17)$ & 0.612 \\
\hline
\end{tabular}




\begin{tabular}{|c|c|c|c|c|c|}
\hline \multirow{6}{*}{$\begin{array}{l}\text { Medications at } \\
\text { discharge - no. } \\
(\%)\end{array}$} & Aspirin & 169/180 (93.9) & $82(91.1)$ & $87(96.7)$ & 0.120 \\
\hline & Clopidogrel & $147 / 180(81.7)$ & $75(83.3)$ & $72(80.0)$ & 0.563 \\
\hline & Beta-blocker & 153/180 (85) & $73(81.1)$ & $80(88.9)$ & 0.144 \\
\hline & Statin & $166 / 180(92.2)$ & $84(93.3)$ & $82(91.1)$ & 0.578 \\
\hline & ACE inhibitor or AR blocker & $144 / 180(80)$ & $67(74.4)$ & $77(85.6)$ & 0.062 \\
\hline & Oral anticoagulant & 21/180 (11.7) & $13(14.4)$ & $8(8.9)$ & 0.246 \\
\hline \multirow{8}{*}{$\begin{array}{l}\text { Achieved } \\
\text { Risk Factor } \\
\text { Control Score* } \\
\text { (at the index } \\
\text { hospitalization) } \\
\text { - no. }(\%)\end{array}$} & LDL-C < $<0$ mg/dL & 42/176 (23.9) & $20(23.0)$ & $22(24.7)$ & 0.788 \\
\hline & Blood Pressure $<140 / 90 \mathrm{mmHg} *$ & $166 / 180(92.2)$ & $79(87.8)$ & $87(96.7)$ & 0.026 \\
\hline & Exercising regularly & 29/179 (16.2) & $11(12.4)$ & $18(20.0)$ & 0.165 \\
\hline & Nonsmoker & $115 / 180(63.9)$ & $54(60)$ & $61(67.8)$ & 0.277 \\
\hline & $\mathrm{BMI}<25 \mathrm{Kg} / \mathrm{m}^{2}$ & $37 / 179(20.7)$ & $19(21.3)$ & $18(20.0)$ & 0.824 \\
\hline & Achieved 5 & $0 / 180(0)$ & 0 & 0 & 1.000 \\
\hline & Achieved 4 & $12 / 180(6.7)$ & $5(5.6)$ & $7(7.8)$ & 0.555 \\
\hline & Achieved $\geq 3$ & $59 / 180(32.8)$ & $26(28.9)$ & $33(36.7)$ & 0.266 \\
\hline $\begin{array}{l}\text { Health Literacy } \\
\text { Questionnaire } \\
\text { (SAHLPA-18)- } \\
\text { no. (\%) }\end{array}$ & $\begin{array}{l}>14 \text { points (good level of Health } \\
\text { literacy) }\end{array}$ & 79/178 (43.9) & 37 (41.6) & $42(47.2)$ & 0.451 \\
\hline \multicolumn{6}{|c|}{$\begin{array}{l}\text { BMI: body mass index; CABG - coronary artery bypass graft; CAD: coronary artery disease; HDL-C: high density lipoprotein cholesterol; IQR: } \\
\text { interquartile range; STEMI: ST elevation myocardial infarction; LDL-C: low density lipoprotein cholesterol; NSTEMI: non-ST elevation myocardial } \\
\text { infarction); PCI: percutaneous coronary intervention; ACE: Angiotensin-converting enzyme; AR: Angiotensin II Receptor; } \\
\text { * Risk Factor Control Score is a cluster of } 5 \text { modifiable risk factors: LDL-C }<70 \mathrm{mg} / \mathrm{dL} \text {, blood pressure (BP) }<140 / 90 \mathrm{mmHg} \text {, regular exercise }(\geq 5 \text { days/week, } \\
30 \text { minutes/session), nonsmoker status, and body mass index (BMI) }<25 \mathrm{~kg} / \mathrm{m} 2 \mathrm{~J} \text {. A patient who achieves all risk factor control would have a combined risk } \\
\text { factor of } 5 ; \text { a patient achieving none of them would be at } 0 . \\
\text { The p-values refer to chi-square test for categorical variables, unpaired Student's t-test for continuous variables with normal distribution, } \\
\text { and Mann-Whitney test for continuous variables with non-normal distribution. }\end{array}$} \\
\hline
\end{tabular}

cardiovascular prevention at 6 months. Secondary outcomes, findings of additional analyses, and post hoc analysis were consistent with the results of the primary outcome. We concluded that SMS intervention did not improve cardiovascular risk factor control in this setting, consisting of a population from a LMIC in a hospital fully embedded in a quality improvement program.

One of the most important mHealth studies in patients with coronary heart disease, the TEXT ME trial, ${ }^{11}$ had positive results using SMS intervention, differently from what was found in IMPACS. After 6 months of follow-up, authors found modest reductions in cholesterol levels, but clinically important impacts in blood pressure levels, BMI, physical exercise, and smoking cessation. Adequate control of four or more modifiable risk factors in the TEXT ME study was also more frequent in the intervention group (28.9\%) versus the control group (10.3\%). Although IMPACS was designed to answer a similar question to that of TEXT ME, the two studies address different contexts.
IMPACS enrolled only patients after ACS, and reasons for non-adherence in this setting are complex, which is different from chronic coronary disease. ${ }^{21-24}$ Moreover, a better adherence to medication in both IMPACS groups may well have minimized the differences between them.

It is important to highlight the significant improvements with the usual care observed in IMPACS, a study developed in a hospital that is part of a pre-established ACS system of care in the city of Belo Horizonte, Brazil. ${ }^{25}$ LDL-C and HDL-C levels in IMPACS were similar to those in the intervention arm of the TEXT ME, and IMPACS patients had a better blood pressure control, regardless of SMS intervention, when compared to the Australian study. ${ }^{11}$ Rates of blood pressure control and smoking cessation, regular physical exercise, and medication adherence (aspirin/statin/beta-blocker use) in the IMPACS were similar to those found in such studies as the medical arm of the COURAGE trial. ${ }^{26}$

An important novelty of IMPACS design was to measure healthy literacy by a validated questionnaire. 
Table 2 - Primary and Secondary Endpoint Analyses at 6-Month Follow-up (intention-to-treat)

\begin{tabular}{|c|c|c|c|c|}
\hline \multicolumn{2}{|l|}{ Outcome } & Intervention (75) & Control (72) & $\begin{array}{c}\text { Odds Ratio } \\
(95 \% \text { CI })\end{array}$ \\
\hline \multicolumn{5}{|l|}{ Primary endpoint } \\
\hline \multicolumn{2}{|c|}{ Achieved 4 or 5 points in a risk factor control score ${ }^{*}$} & $12(16.2)$ & $15(20.8)$ & $0.73(0.32-1.70)$ \\
\hline \multicolumn{5}{|l|}{ Secondary endpoints } \\
\hline \multicolumn{2}{|l|}{ LDL-C $<70 \mathrm{mg} / \mathrm{dL}$} & $34 / 75(45.3)$ & $27 / 72(37.5)$ & $1.38(0.71-2.67)$ \\
\hline \multicolumn{2}{|l|}{ Blood pressure $<140 / 90 \mathrm{mmHg}$} & 60/74 (81.1) & $62 / 72(86.1)$ & $0.64(0.27-1.55)$ \\
\hline \multicolumn{2}{|l|}{ Exercising regularly } & $30 / 75(40.0)$ & 29/72 (40.3) & $0.99(0.51-1.91)$ \\
\hline \multicolumn{2}{|l|}{ Nonsmoker* } & $62 / 75(82.7)$ & $58 / 72(80.6)$ & $1.15(0.50-2.65)$ \\
\hline \multicolumn{2}{|l|}{$\mathrm{BMI}<25 \mathrm{Kg} / \mathrm{m}^{2}$} & $14 / 75(18.7)$ & $15 / 71(21.1)$ & $0.86(0.38-1.93)$ \\
\hline \multicolumn{2}{|l|}{ Medication adherence } & 66/75 (88.0) & 67/72 (93.1) & $0.55(0.17-1.72)$ \\
\hline \multirow{3}{*}{$\begin{array}{l}\text { Achieved Risk } \\
\text { Control Score }^{\dagger}\end{array}$} & Achieved 5 & $3 / 75(4.0)$ & $1 / 72(1.4)$ & $2.96(0.30-29.12)$ \\
\hline & Achieved 4 & 9/75 (12.0) & 14/72 (19.4) & $0.56(0.23-1.40)$ \\
\hline & Achieved $\geq 3$ & $43 / 75(57.3)$ & $40 / 72(55.6)$ & $1.07(0.56-2.06)$ \\
\hline \multicolumn{2}{|l|}{ Rehospitalization } & 15/77(19.5) & 24/73 (32.9) & $0.49(0.23-1.05)$ \\
\hline \multicolumn{2}{|l|}{ Cardiovascular death } & 1/77 (1.3) & $1 / 73(1.4)$ & $0.95(0.06-15.43)$ \\
\hline \multicolumn{2}{|l|}{ Death from any cause } & 2/77 (2.6) & 1/73 (1.4) & $1.92(0.17-21.63)$ \\
\hline \multicolumn{5}{|c|}{$\begin{array}{l}\text { LDL-C: low density lipoprotein cholesterol; BMI: body mass index); } \\
\text { *Two patients who said "no" to the question "are you smoking after hospitalization?" were reclassified as smokers by a Carbon Monoxide Meter Breath Test } \\
\text { (one patient in the intervention group and one patient in the control group); } \\
\text { t Risk Factor Control Score is a cluster of } 5 \text { modifiable risk factors: } L D L-C<70 \mathrm{mg} / \mathrm{dL} \text {, blood pressure (BP) }<140 / 90 \mathrm{mmHg} \text {, regular exercise ( } \geq 5 \text { days/week, } \\
\left.30 \text { minutes/session), nonsmoker status, and body mass index (BMI) }<25 \mathrm{~kg} / \mathrm{m}^{2}\right] \text {. A patient who achieves all risk factor control would have a combined risk } \\
\text { factor of 5; a patient achieving none of them would be at } 0 \text {. } \\
\text { The groups were compared by chi-square test and the results presented as odds ratio, including the } 95 \% \text { confidence interval (95\% CI) }\end{array}$} \\
\hline
\end{tabular}

Understanding of SMS sent to patients in LMIC might not be the same as in high-income countries, possibly leading to worse results from m-Health intervention. ${ }^{12}$ The applied questionnaire (SAHLPA-18) showed that less than half of the patients enrolled in this trial had adequate health literacy. This data, added to the economiceducational context described in Table 1, reveal that the lowest educational level of the population in Brazil was studied in IMPACS. Despite lower health literacy, this condition did not influence the primary endpoint in an additional analysis.

Despite being exploratory, some findings should be further investigated in a study with adequate power for such an analysis. In the intervention group, hospitalization rates tended to be lower in the intention to treat analysis as well as in the per-protocol analysis. Lower hospitalizations after ACS are clinically important, since they may result in fewer deaths and lower costs. ${ }^{8,9}$
Another interesting finding was the higher rate of moderate exercise by accelerometer analysis in the group receiving SMS. This data is in agreement with other published studies which showed evidence, although not definite, of short-term benefits of using SMS aimed at increasing the level of regular physical exercise. ${ }^{27}$

There is a significant effort to translate cardiovascular science into guidelines to assist health professionals in the management of coronary disease. Given these aspects, the IMPACS study strengthens the importance of organized systems of ACS care that should also include outpatient care after discharge - an underused effective strategy that must be encouraged. The costs involved and infrastructure required markedly, a specialized healthcare staff - may limit the development of such a model of care in low resourced region,s and SMS strategies may be a good solution in this adverse condition. 
Table 3 - Follow-up Characteristics (at 6-month visit)

\begin{tabular}{|c|c|c|c|c|c|}
\hline Char & cteristic & Total (147) & Intervention (75) & Control (72) & p-value \\
\hline \multirow{7}{*}{$\begin{array}{l}\text { Medications at } \\
\text { 6-month follow up - } \\
\text { no. (\%) }\end{array}$} & Aspirin & $135(91.8)$ & $68(91.9)$ & $67(93.1)$ & 0.790 \\
\hline & Clopidogrel & $116(78.9)$ & $58(77.3)$ & $58(80.6)$ & 0.632 \\
\hline & Beta-blocker & $125(85.0)$ & $60(80.0)$ & $65(90.3)$ & 0.081 \\
\hline & Statin & $135(91.8)$ & $70(93.3)$ & $65(90.3)$ & 0.499 \\
\hline & $\begin{array}{c}\text { ACE inhibitor or AR } \\
\text { blocker }\end{array}$ & $126(85.7)$ & $64(85.3)$ & $62(86.1)$ & 0.893 \\
\hline & Oral anticoagulant & $21(14.2)$ & $10(13.3)$ & $11(15.3)$ & 0.736 \\
\hline & Insulin & $13(8.8)$ & $5(6.7)$ & $8(11.1)$ & 0.343 \\
\hline \multirow{8}{*}{$\begin{array}{l}\text { Clinical Data - Mean } \\
(\mathrm{SD}), \text { no. }(\%) \text {, median } \\
(\mathrm{IQR})\end{array}$} & Body mass index & $28.0(26.0-31.0)$ & $28.0(25.8-31.1)$ & $28.7(26.0-30.9)$ & 0.576 \\
\hline & $\begin{array}{c}\text { Total-Cholesterol- mg/ } \\
\mathrm{dL}\end{array}$ & $150.0(128.0-176.0)$ & $147.0(126.0-173.5)$ & $151.0(129.0-183.0)$ & 0.583 \\
\hline & $\mathrm{LDL}-\mathrm{C}-\mathrm{mg} / \mathrm{dL}$ & $77.0(57.0-99.0)$ & $77.0(60.0-100.0)$ & $77.0(54.0-104.0)$ & 0.815 \\
\hline & $\mathrm{HDL}-\mathrm{C}-\mathrm{mg} / \mathrm{dL}$ & $40.0(34.0-47.0)$ & $39.0(34.0-47.0)$ & $41.0(35.0-49.0)$ & 0.203 \\
\hline & Triglycerides - mg/dL & 149.5 (110.0-202.2) & $150.0(109.0-200.0)$ & $149.0(110.0-207.0)$ & 0.795 \\
\hline & $\begin{array}{c}\text { Systolic Blood } \\
\text { pressure - mm Hg }\end{array}$ & $121.2( \pm 17.3)$ & $121.5( \pm 19.0)$ & $121.0( \pm 15.4)$ & 0.860 \\
\hline & $\begin{array}{c}\text { Diastolic Blood } \\
\text { pressure - mm Hg }\end{array}$ & $73.5( \pm 11.3)$ & $73.7( \pm 12.3)$ & $73.2( \pm 10.3)$ & 0.813 \\
\hline & Heart rate $-/ \mathrm{min}$ & $67.0(61.0-76.0)$ & $68.0(61.0-77.0)$ & $67.0(61.0-75.2)$ & 0.813 \\
\hline \multicolumn{6}{|c|}{$\begin{array}{l}\text { HDL-C: high density lipoprotein cholesterol; IQR: interquartile range; LDL-C: low density lipoprotein cholesterol; ACE: Angiotensin-converting enzyme } \\
\text { AR: Angiotensin II Receptor. } \\
\text { The p-values refer to chi-square test for categorical variables, unpaired Student's t-test for continuous variables with normal distribution, ano } \\
\text { Mann-Whitney test for continuous variables with non-normal distribution. }\end{array}$} \\
\hline
\end{tabular}

Limitations of our study should be considered. First, we decided to use a combined surrogate outcome. Second, most of our patients used simvastatin, $40 \mathrm{mg} / \mathrm{day}$, as the access to a high-intensity statin is limited for patients in the Brazilian public health care system, which may have affected the achievement of LDL-C goals. Third, although the IPAQ-SF is a validated questionnaire, it has important limitations, which have been previously debated, ${ }^{18}$ and only a few patients could use an accelerometer for a better analysis of their physical exercise level. Fourth, 20 participants $(26.6 \%)$ in the intervention group reported not having received IMPACS SMS, though our system confirmed that they had been sent, which may have contributed to the loss of study power, raising the possibility of a type II error. The recent widespread use of cellphone messaging apps, instead of SMS - which are charged in some plans - may have additionally accounted for this. However, different analyses performed in IMPACS were consistent with the primary outcome result, reinforcing our findings. Furthermore, as 13 of the 20 participants (65\%) changed their telephone contact number during the study or provided a non-personal phone upon enrollment (Table 4), this limitation is inherent to the use of mHealth tools. In this sense, messaging apps have the advantage of not being linked to mobile numbers. And finally, the results should not be extrapolated to centers with different ACS follow-up care and to other regions of Brazil, especially those with different socioeconomic and healthcare backgrounds.

On the other hand, our study has a number of strengths that should also be considered. First, IMPACS was a randomized trial that targeted a low-income population with low indices of adequate health literacy, which is an important gap, since most SMS studies came 

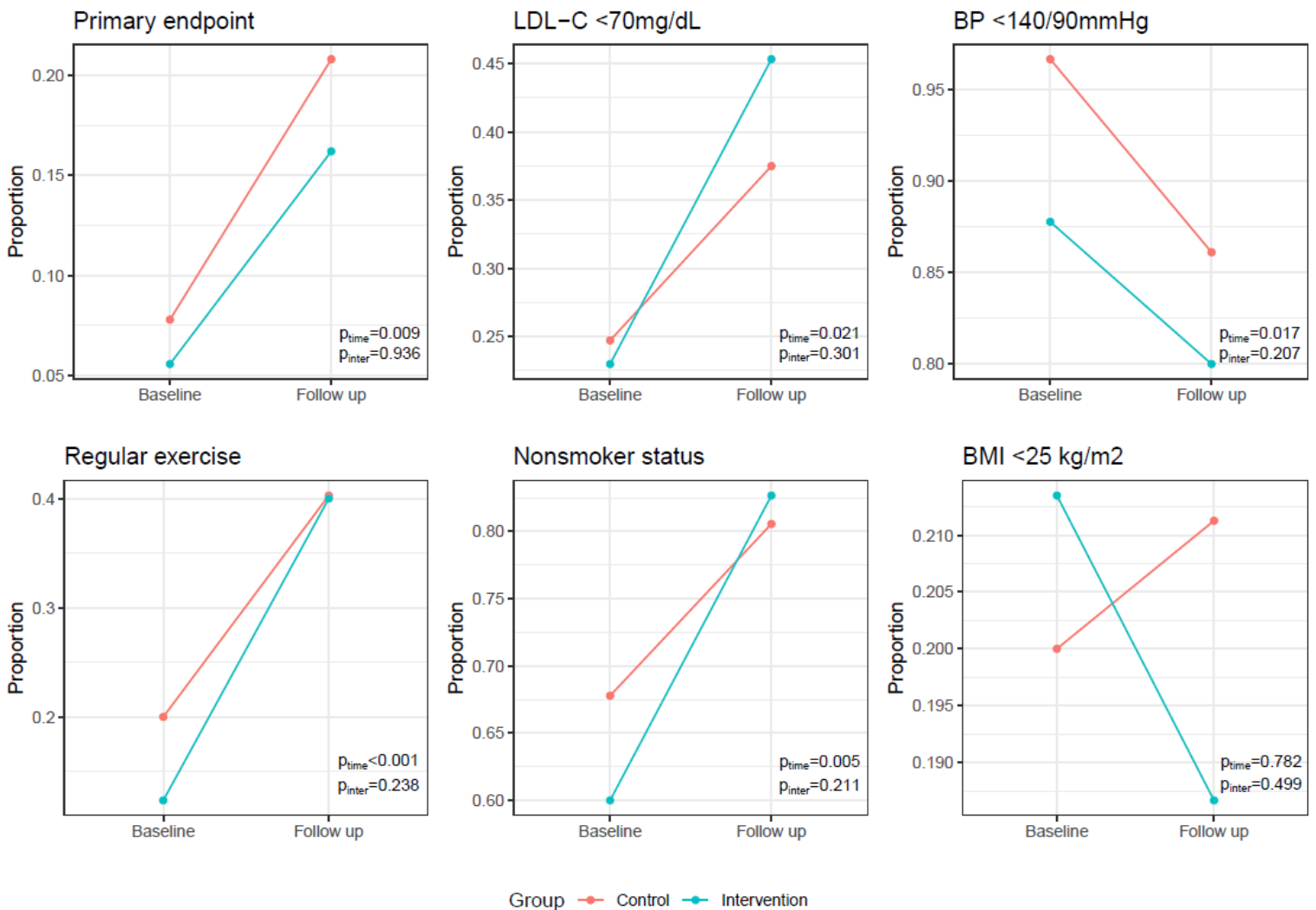

Figure 2 - Longitudinal post hoc analysis - primary outcome and components of the primary outcome p-value was calculated using Generalized Estimation Equations (GEE)

from high-income countries. ${ }^{10}$ Second, the development of a dedicated software to send one-way SMS overcomes an important barrier to the implementation of this simple and inexpensive technology in LMIC. Third, the messages addressed, at the same time, several essential conditions for cardiovascular prevention, all with a language adapted to the cultural and social levels of the target population. Therefore, $90 \%$ of those who reported receiving the SMS declared that they understood and considered the messages helpful for their treatment.

\section{Conclusion}

In patients discharged after ACS, the SMS intervention did not significantly improve cardiovascular risk factor control at 6 months compared to standard care in a
Brazilian public university hospital, where post-ACS outpatient care is already structured. However, the number of patients studied was small, and the results cannot be considered definitive.

\section{Author contributions}

Conception and design of the research: Passaglia LG, Brant L, Ribeiro A. Acquisition of data: Passaglia LG. Analysis and interpretation of the data: Passaglia LG, Brant L, Ramos B, Ribeiro A. Statistical analysis: Passaglia LG, Brant L, Silva JLP, Ramos B, Ribeiro A. Writing of the manuscript: Passaglia LG, Brant L, Ramos B, Ribeiro A.Critical revision of the manuscript for intellectual content: Passaglia LG, Brant L, Silva JLP, Ramos B, Ribeiro A. 
Table 4 - Primary and Secondary Endpoint Analyses at 6-Month Follow-up (per-protocol)

Outcome

$$
\text { Primary endpoint }
$$

\begin{tabular}{|c|c|c|c|}
\hline Achieving 4 or 5 points in a risk factor control score* & $10(18.2)$ & $17(18.7)$ & $0.97(0.41-2.30)$ \\
\hline \multicolumn{4}{|l|}{ Primary endpoints } \\
\hline $\mathrm{LDL}-\mathrm{C}<70 \mathrm{mg} / \mathrm{dL}$ & $26(47.3)$ & $34(37)$ & $1.53(0.78-3.01)$ \\
\hline Blood pressure $<140 / 90 \mathrm{~mm} \mathrm{Hg}$ & $47(85.5)$ & $75(81.5)$ & $1.33(0.53-3.33)$ \\
\hline Exercising regularly & $21(38.2)$ & $38(41.3)$ & $0.88(0.44-1.74)$ \\
\hline Nonsmoker & $46(83.6)$ & $74(80.4)$ & $1.24(0.51-3.00)$ \\
\hline $\mathrm{BMI}<25 \mathrm{Kg} / \mathrm{m}^{2}$ & $10(18.2)$ & $19(20.9)$ & $0.84(0.36-1.98)$ \\
\hline Medication adherence & $49(89.1)$ & $84(91.3)$ & $0.78(0.25-2.37)$ \\
\hline \multirow{3}{*}{$\begin{array}{l}\text { Achieved Risk Factor } \\
\text { Control Score }^{+}\end{array}$} & $2(3.6)$ & $2(2.2)$ & $1.70(0.23-12.41)$ \\
\hline & $8(14.5)$ & $15(16.3)$ & $0.87(0.34-2.22)$ \\
\hline & $35(63.6)$ & $48(52.2)$ & $1.60(0.81-3.18)$ \\
\hline Rehospitalization $^{+}$ & $9(15.8)$ & $30(32.3)$ & $0.39(0.17-0.91)$ \\
\hline Cardiovascular death & $1(1.8)$ & $1(1.1)$ & $1.64(0.10-26.79)$ \\
\hline Death from any cause & $2(3.5)$ & $1(1.1)$ & $3.34(0.30-37.76)$ \\
\hline \multicolumn{4}{|c|}{$\begin{array}{l}\text { LDL-C: low density lipoprotein cholesterol; BMI : body mass index; } \\
\text { * Risk Factor Control Score is a cluster of } 5 \text { modifiable risk factors: } L D L-C<70 \mathrm{mg} / \mathrm{dL}, \text { blood pressure }(B P)<140 / 90 \mathrm{mmHg}, \text { regular exercise }(\geq 5 \text { days/week, } 30 \\
\left.\text { minutes/session), nonsmoker status, and body mass index }(B M I)<25 \mathrm{~kg} / \mathrm{m}^{2}\right] . \text { A patient who achieves all risk factor control would have a combined risk factor } \\
\text { of 5; a patient achieving none of them would be at } 0 ;+P=0.026 \text {. } \\
\text { The groups were compared by chi-square test and the results presented as odds ratio, including the 95\% confidence interval (95\% CI) }\end{array}$} \\
\hline
\end{tabular}

\section{Potential Conflict of Interest}

No potential conflict of interest relevant to this article was reported.

\section{Sources of Funding}

Dr. Nascimento was supported in part by $\mathrm{CNPq}$ (Bolsa de produtividade em pesquisa, 312382/2019-7), by the Edwards Lifesciences Foundation (Improving the Prevention and Detection of Heart Valve Disease Across the Lifespan, 2021) and by FAPEMIG (grant APQ-000627-20). Dr Ribeiro is supported in part by CNPq (310679/2016-8 and 465518/2014-1) and by FAPEMIG (PPM-00428-17 and RED-00081-16).

\section{References}

1. GBD 2016 Causes of Death Collaborators. Global, Regional, and National Age-Sex Specific Mortality for 264 Causes of Death, 1980-2016: A Systematic Analysis for the Global Burden of Disease Study 2016. Lancet. 2017;390(10100):1151-210. doi: 10.1016/S0140-6736(17)32152-9.

\section{Study Association}

This article is part of the thesis of Doctoral submitted by Luiz Passaglia, from Universidade Federal de Minas Gerais.

\section{Ethics approval and consent to participate}

This study was approved by the Ethics Committee of the Universidade Federal de Minas Gerais under the protocol number 2.054.294. All the procedures in this study were in accordance with the 1975 Helsinki Declaration, updated in 2013. Informed consent was obtained from all participants included in the study.

2. França EB, Passos VMA, Malta DC, Duncan BB, Ribeiro ALP, Guimarães MDC, et al. Cause-Specific Mortality for 249 Causes in BRAZIL and States During 1990-2015: A Systematic Analysis for the Global Burden of Disease Study 2015. Popul Health Metr. 2017;15(1):39. doi: 10.1186/s12963-017-0156-y. 
3. Ribeiro ALP, Duncan BB, Brant LCC, Lotufo PA, Mill JG, Barreto SM Cardiovascular Health in Brazil: Trends and Perspectives. Circulation. 2016;133(4):422-33. doi: 10.1161/CIRCULATIONAHA.114.008727.

4. Brant LCC, Nascimento BR, Passos VMA, Duncan BB, Bensenõr IJM, Malta DC, et al. Variations and Particularities in Cardiovascular Disease Mortality in Brazil and Brazilian States in 1990 and 2015: Estimates from the Global Burden of Disease. Rev Bras Epidemiol. 2017;20(Suppl 1):11628. doi: 10.1590/1980-5497201700050010.

5. Zipes DP, Libby P, Bonow RO, Mann DL, Tomaselli GF, editors. Braunwald's Heart Disease: A Textbook of Cardiovascular Medicine. 10th ed. Philadelphia: Elsevier; 2012

6. Benjamin EJ, Virani SS, Callaway CW, Chamberlain AM, Chang AR, Cheng S, et al. Heart Disease and Stroke Statistics-2018 Update: A Repor From the American Heart Association. Circulation. 2018;137(12):e67-e492. doi: 10.1161/CIR.0000000000000558

7. Roffi M, Patrono C, Collet JP, Mueller C, Valgimigli M, Andreotti F, et al. 2015 ESC Guidelines for the Management of Acute Coronary Syndromes in Patients Presenting Without Persistent ST-Segment Elevation: Task Force for the Management of Acute Coronary Syndromes in Patients Presenting without Persistent ST-Segment Elevation of the European Society of Cardiology (ESC). Eur Heart J. 2016;37(3):267-315. doi: 10.1093/ eurheartj/ehv320.

8. Ibanez B, James S, Agewall S, Antunes MJ, Bucciarelli-Ducci C, Bueno H, et al. 2017 ESC Guidelines for the Management of Acute Myocardial Infarction in Patients Presenting with ST-Segment Elevation: The Task Force for the Management of Acute Myocardial Infarction in Patients Presenting with ST-Segment Elevation of the European Society of Cardiology (ESC). Eur Heart J. 2018;39(2):119-77. doi: 10.1093/eurheartj/ehx393.

9. Fleg JL, Forman DE, Berra K, Bittner V, Blumenthal JA, Chen MA, et al. Secondary Prevention of Atherosclerotic Cardiovascular Disease in Older Adults: A Scientific Statement from the American Heart Association. Circulation. 2013;128(22):2422-46. doi: 10.1161/01. cir.0000436752.99896.22.

10. Marcolino MS, Oliveira JAQ, D'Agostino M, Ribeiro ALP, Alkmim MBM, Novillo-Ortiz D. The Impact of mHealth Interventions: Systematic Review of Systematic Reviews. JMIR Mhealth Uhealth. 2018;6(1):e23. doi: 10.2196/mhealth. 8873

11. Chow CK, Redfern J, Hillis GS, Thakkar J, Santo K, Hackett ML, et al. Effect of Lifestyle-Focused Text Messaging on Risk Factor Modification in Patients With Coronary Heart Disease: A Randomized Clinical Trial. JAMA. 2015;314(12):1255-63. doi: 10.1001/jama.2015.10945.

12. Marcolino MS, Oliveira JAQ, Ribeiro ALP. Text messaging for prevention and treatment of cardiovascular disease: time to move on. Heart. 2017;103(12):893-94. doi: 10.1136/heartjnl-2016-311135.

13. Kruse C, Betancourt J, Ortiz S, Valdes Luna SM, Bamrah IK, Segovia N. Barriers to the Use of Mobile Health in Improving Health Outcomes in Developing Countries: Systematic Review. J Med Internet Res. 2019;21(10):e13263. doi: 10.2196/13263.

14. Simpson SH, Eurich DT, Majumdar SR, Padwal RS, Tsuyuki RT, Varney $\mathrm{J}$, et al. A meta-Analysis of The Association between Adherence to Drug Therapy and Mortality. BMJ. 2006;333(7557):15. doi: 10.1136/ bmj.38875.675486.55.
15. Passaglia LG, Brant LCC, Nascimento BR, Ribeiro ALP. Impact of Text Messages in a Middle-Income Country to Promote Secondary Prevention After Acute Coronary Syndrome (IMPACS): A Randomized Trial. Medicine. 2019;98(22):e15681. doi: 10.1097/MD.0000000000015681.

16. Sociedade Brasileira de Cardiologia. Programa Boas Práticas Clínicas em Cardiologia [Internet]. São Paulo: 2021 [cited 202118 Jun]. Available from: http://www.cardiol.br/boaspraticasclinicas

17. Gusmão LL, Ribeiro ALP, Souza-Silva MVR, Gomes PR, Beleigoli AM, Cardoso CS, et al. Implementation of a Text Message Intervention to Promote Behavioural Change and Weight Loss Among Overweight and Obese Brazilian Primary Care Patients. J Telemed Telecare. 2019;25(8):47683. doi: 10.1177/1357633X18782092.

18. Lee PH, Macfarlane DJ, Lam TH, Stewart SM. Validity of the International Physical Activity Questionnaire Short Form (IPAQ-SF): A Systematic Review. Int J Behav Nutr Phys Act. 2011;8:115. doi: 10.1186/1479-5868-8-115.

19. Delgado AB, Lima ML. Contributo para a Validação Concorrente de uma Medida de Adesão aos Tratamentos. Psicol. Saude Doenças. 2001;2(2):81-100.

20. Apolinario D, Braga RC, Magaldi RM, Busse AL, Campora F, Brucki S, et al. Short Assessment of Health Literacy for Portuguese-speaking Adults. Rev Saude Publica. 2012;46(4):702-11. doi: 10.1590/s0034-89102012005000047.

21. Bagnall AJ, Yan AT, Yan RT, Lee CH, Tan M, Baer C, et al. Optimal Medical Therapy for Non-ST-segment-elevation Acute Coronary Syndromes: Exploring why Physicians do not Prescribe Evidencebased Treatment and why Patients Discontinue Medications after Discharge. Circ Cardiovasc Qual Outcomes. 2010;3(5):530-7. doi: 10.1161/ CIRCOUTCOMES.109.919415.

22. Gencer B, Rodondi N, Auer R, Räber L, Klingenberg R, Nanchen D, et al. Reasons for Discontinuation of Recommended Therapies According to the Patients After Acute Coronary Syndromes. Eur J Intern Med. 2015;26(1):5662. doi: 10.1016/j.ejim.2014.12.014.

23. Cheng K, Ingram N, Keenan J, Choudhury RP. Evidence of Poor Adherence to Secondary Prevention after Acute Coronary Syndromes: Possible Remedies Through the Application of New Technologies. Open Heart. 2015;2(1):e000166. doi: 10.1136/openhrt-2014-000166.

24. Naderi SH, Bestwick JP, Wald DS. Adherence to Drugs That Prevent Cardiovascular Disease: Meta-Analysis on 376,162 Patients. Am J Med. 2012;125(9):882-7.e1. doi: 10.1016/j.amjmed.2011.12.013.

25. Marcolino MS, Brant LCC, Araujo JG, Nascimento BR, Castro LR, Martins $\mathrm{P}$, et al. Implementation of the Myocardial Infarction System of Care in City of Belo Horizonte, Brazil. Arq Bras Cardiol. 2013;100(4):307-14. doi: 10.5935/abc.20130054

26. Boden WE, O'Rourke RA, Teo KK, Hartigan PM, Maron DJ, Kostuk WI, et al. Optimal Medical Therapy with or Without PCI for Stable Coronary Disease. N Engl J Med. 2007;356(15):1503-16. doi: 10.1056/NEJMoa070829.

27. Free C, Phillips G, Galli L, Watson L, Felix L, Edwards P, et al. The Effectiveness of Mobile-health Technology-based Health Behaviour Change or Disease Management Interventions for Health Care Consumers: A Systematic Review. PLoS Med. 2013;10(1):e1001362. doi: 10.1371/journal. pmed.1001362.

\section{*Supplemental Materials}

For additional information, please click here. 